\title{
Chemical composition and antibacterial activities of the ethanol extracts from the leaves and tubers of Amorphophallus pusillus
}

\author{
Hong Thien $\operatorname{Van}^{1}$, Hong Hai My Nguyen ${ }^{1}$, Nguyen Tuong An Huynh ${ }^{2}$, Van Son Le ${ }^{3} \&$ Gia Buu Tran ${ }^{1 *}$ \\ ${ }^{1}$ Institute of Biotechnology \& Food-technology, Industrial University of Ho Chi Minh City, 12 Nguyen Van Bao Street, Go Vap District, Ho Chi Minh City, \\ Vietnam \\ ${ }^{2}$ Office of Postgraduate Management, Industrial University of Ho Chi Minh City, 12 Nguyen Van Bao Street, Go Vap District, Ho Chi Minh City, Vietnam \\ ${ }^{3}$ Binh Chau-Phuoc Buu Nature Reserve, Bung Rieng ward, Xuyen Moc District, Ba Ria-Vung Tau Province, Vietnam \\ * Email: trangiabuu@iuh.edu.vn
}

\section{ARTICLE HISTORY}

Received: 16 January 2020

Accepted: 27 February 2020

Published: 02 June 2020

\section{KEYWORDS}

antibacterial activities

Amorphophallus pusillus

ethanol extracts

LC/MS

\section{ABSTRACT}

Amorphophallus pusillus is a rare species which is found only in Binh Chau-Phuoc Buu Nature Reserve. In this study, we determined 7 flavonoid compounds in A. pusillus tubers and leaves, including of vitexin, orientin, vitexin 2"-O-glucoside, cyanidin 3-Orutinoside, pelargonidin 3-O-glucoside, schaftoside, and peonidin 3-O-rutinoside via liquid chromatography-mass spectrometry (LC/MS). Furthermore, we have proved the antibacterial activities of ethanol extracts obtained from $A$. pusillus leaves and tubers for the first time. The data revealed that ethanol extracts could inhibit the growth of 6 tested microorganisms, such as Bacillus cereus, Escherichia coli, Pseudomonas aeruginosa, Salmonella enteritidis, Salmonella typhimurium and Staphylococcus aureus. These data suggested the potential application of ethanol extracts isolated from this species as natural antimicrobial agents for treatment of infection caused by bacteria, especially in dermatologic and enteric infection.

\section{Introduction}

Amorphophallus is a large genus of the Araceae family which comprises of 200 species over the world with 30 species in Vietnam (1-4). The application of several species of this genus in food industry and medicine has been documented. For example, the root of $A$. paeoniifolius contains high concentration of essential minerals, starch, carbohydrate, which suggests the potential application of this species in food industry (5). Furthermore, analgesic, anti-helmintic and antimicrobial activities of $A$. paeoniifolius extracts also have been recorded (5). Accordingly, six plant species of Amorphophallus genus, including A. krausei, $A$. yunnanensis, A. yuloensis, A. paeoniifolius, A. konjac and $A$. corrugatus recorded in Northern mountain provinces of Vietnam, contain glucomannan, a plant component with many health benefits, such as treatment for constipation, improving of type 2 diabetes, lowering blood cholesterol and sugar (4). Recently, it has been revealed that methanol extract from A. lanceolatus tuber contained 12 chemical compounds and could hinder the growth of 6 bacterial strains (6).

Amorphophallus pusillus was described by Hetterschied and Serebryanyi from Xuyen Moc District, Ba Ria-Vung Tau Province, Vietnam (7). This is an endemic species of Vietnam till date, $A$. pusillus has only been mentioned. In some studies on the genus Amorphophallus and flora Vietnam, but its chemical composition and bioactivities have not been studied yet. The previous studies about the antibacterial activity of other members of Amorphophallus, including A. paeoniifolius and A. lanceolatus, give a possibility that $A$. pusillus extract has the bacterial activity $(5,6)$. In this study, we elucidated the chemical composition via liquid chromatography-mass spectrometry (LC/MS) and proved antibacterial activities of ethanol extracts of $A$. pusillus leaves and tubers, which provides the information for further application and improves the value of $A$. pusillus.

(C) Van et al.(2020). This is an open-access article distributed under the terms of the Creative Commons Attribution License, which permits unrestricted use, distribution, and reproduction in any medium, provided the original author and source are credited (https://creativecommons.org/licenses/by/4.0/).

To cite this article: Van H T, Nguyen H H M, Huynh N T A, Le V S, Tran G B. Chemical composition and antibacterial activities of the ethanol extracts from the leaves and tubers of Amorphophallus pusillus. Plant Science Today. 2020;7(2):296-301. https://doi.org/10.14719/pst.2020.7.2.732 


\section{Materials and Methods}

\section{Plant material}

Specimens of $A$. pusillus (1 kg) were collected from Binh Chau-Phuoc Buu Nature Reserve, Bung Rieng Ward, Xuyen Moc District, Ba Ria-Vung Tau Province, location of about $10^{0} 32^{\prime} 55^{\prime \prime N}$; $107^{0} 29^{\prime} 12^{\prime} \mathrm{E}$, May 17 , 2019, $31 \mathrm{~m}$ in elevation (Fig. 1). The plant was identified by Dr. Hong Thien Van (Department of Biotechnology, Institute of Biotechnology and Foodtechnology, Industrial University of Ho Chi Minh City, Vietnam) and a voucher specimen of this material was deposited at the Herbarium of Binh Chau-Phuoc Buu Nature Reserve (H.T. Van 202).

\section{Microorganisms}

The antibacterial activity of the extract was evaluated using six bacterial strains, including two Grampositive bacteria (Bacillus cereus (ATCC 11774) and Staphylococcus aureus (ATCC 25923), and four Gramnegative bacteria (Escherichia coli (ATCC 25922), Pseudomonas aeruginosa (ATCC 27853), Salmonella enteritidis (ATCC 13976), Salmonella typhimurium (ATCC 13311). All of bacterial strains were provided from the microbiology collection, Department of Biotechnology, Institute of Food and Biotechnology, Industrial University of Ho Chi Minh city, Vietnam. The strains were stored in $20 \%$ glycerol solution at $20^{\circ} \mathrm{C}$ and subsequently re-activated in Luria-Bertani broth at $37^{\circ} \mathrm{C}$ for $24 \mathrm{~h}$ before the experiments.

\section{Extraction procedure}

The ethanol extracts of $A$. pusillus leaves and tubers were prepared (6). Briefly, $500 \mathrm{~g}$ of fresh leaves or sliced tubers $\mathrm{f} A$. pusillus were moderately dried at $50^{\circ} \mathrm{C}$ for 1-2 days until constant weight and milled to dried powder by electric blender (HR- 2068, Philips, China). $100 \mathrm{~g}$ of the resulting powder was macerated in $1000 \mathrm{ml}$ of $99 \%$ ethanol for 7 days at room temperature and filtered through filter paper to collect the extract. The extract was then condensed under vacuum pressure at $60^{\circ} \mathrm{C}$ to obtain the brown medicinal paste. To ensure the absolute absence of ethanol in the paste, sublimation dryer was utilized. The obtained extracts were stored at $4^{\circ} \mathrm{C}$ until further use.

\section{Liquid chromatography mass spectrometry (LC/MS)}

For identification of the components in the extract, LC-MS analysis was performed at the Central Laboratory for Analysis, University of Science, Vietnam National University of Ho Chi Minh City. Aliquots of ethanol extracts were injected into HPLC Agilent 1200 infinity liquid chromatography system (Agilent Technologies, CA, USA) coupled with

Table 1. Gradient elution program for the chromatographic separation

\begin{tabular}{ccc}
\hline Time (min) & Solvent $^{*}$ & Solvent $^{*}$ \\
\hline 0 & 90 & 10 \\
\hline 15 & 0 & 100 \\
\hline 30 & 0 & 100 \\
\hline 31 & 90 & 10 \\
\hline 40 & 90 & 10 \\
\hline
\end{tabular}

(*): presented as the percentage of volume of mobile phase

Solvent A: Deionized water with $0.1 \%$ formic acid

Solvent B: Acetonitrile with $0.1 \%$ formic acid

MicroTOF-QII mass spectrometer (Bruker Daltonics, Germany). The components were separated on ACE3$\mathrm{C}_{18}$ analytical column $(4.6 \times 150 \mathrm{~mm}, 3.5 \mu \mathrm{m})$ as stationary phase and the temperature was kept at $40^{\circ} \mathrm{C}$. The mobile phase used consisted of deionized

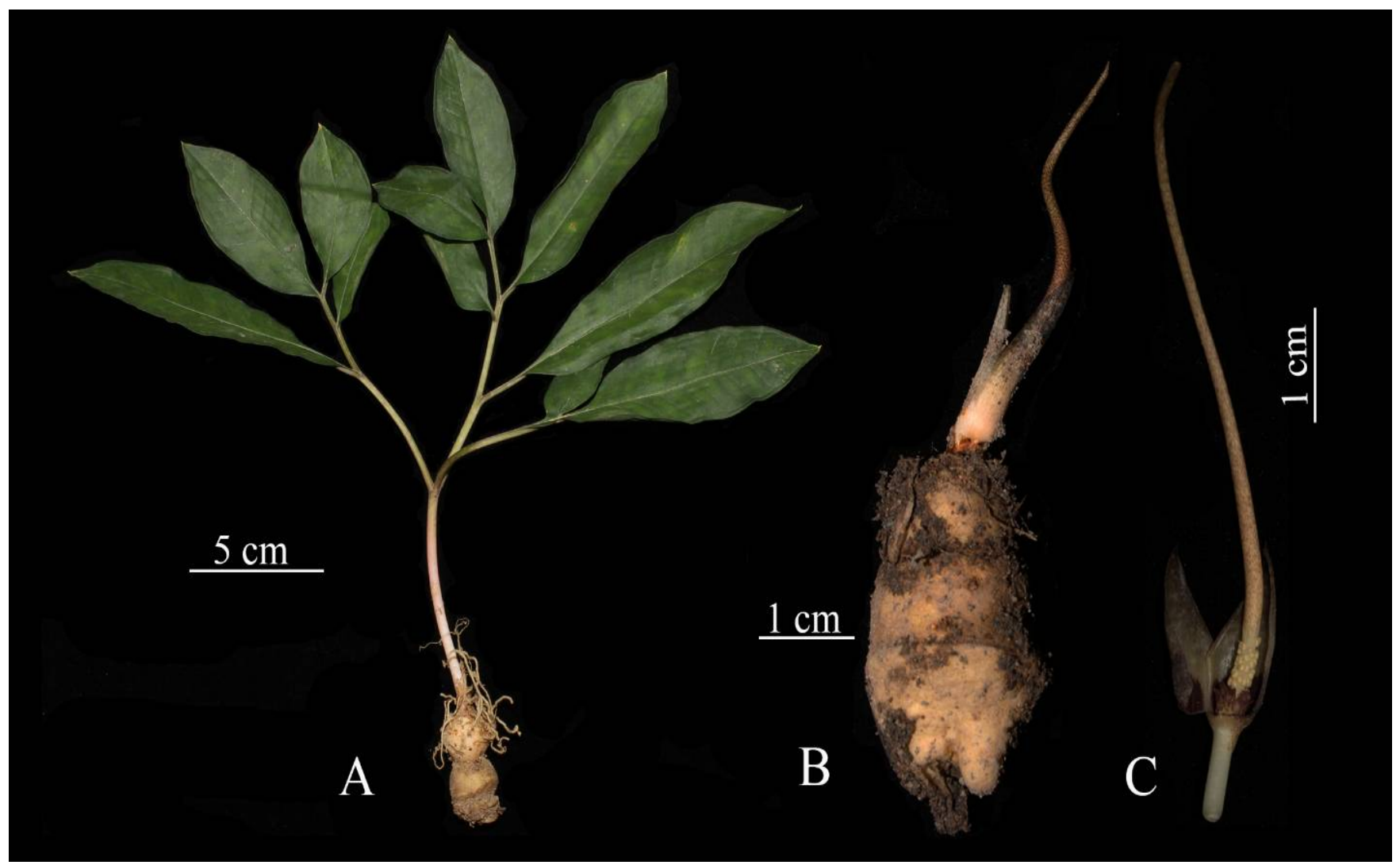

Fig. 1. Amorphophallus pusillus. A. Tuber and leaf, B. Tuber and spathe, C. Spadix 


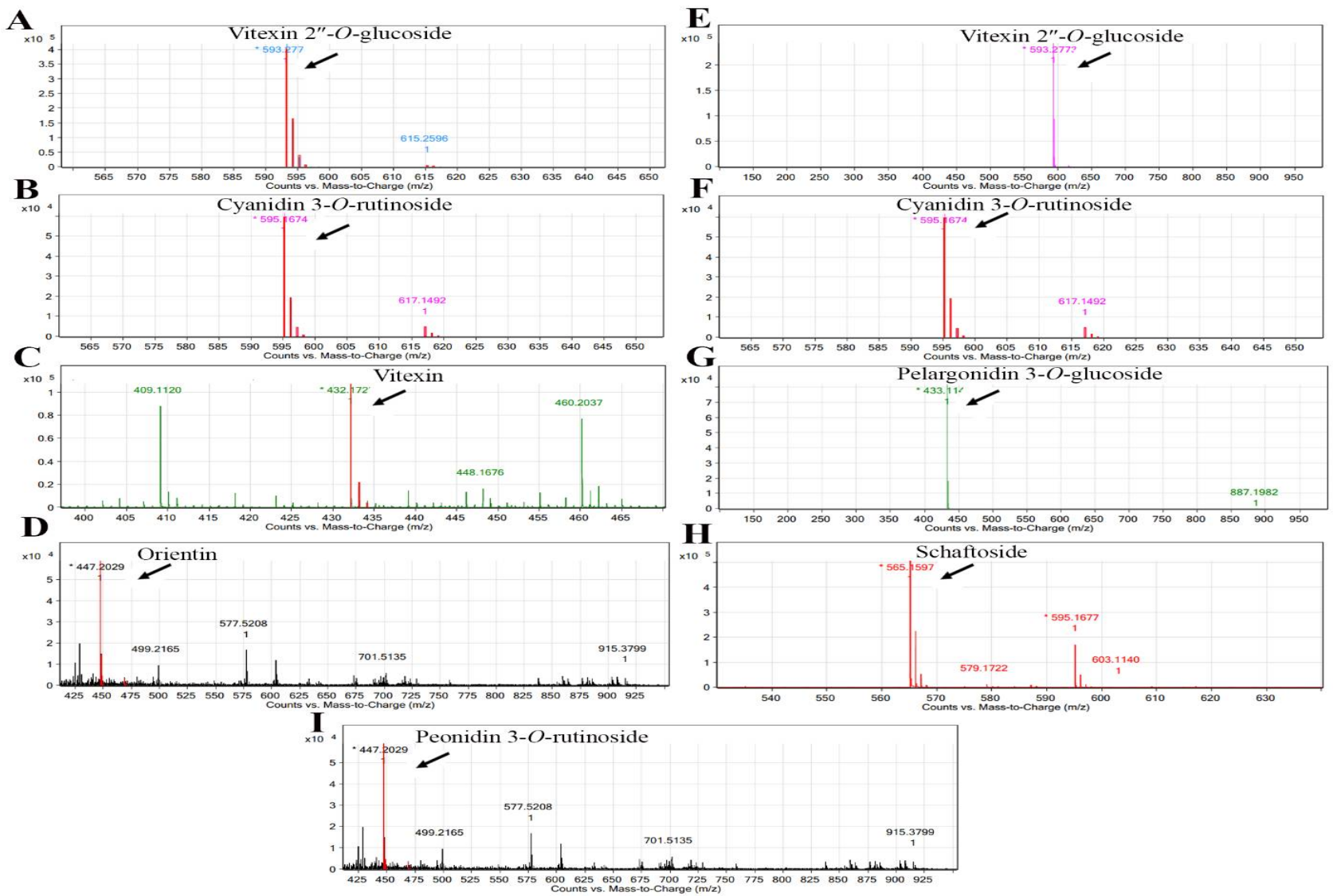

Fig. 2. Mass spectrometry diagrams of 7 compounds of ethanol extracts of A. pusillus leaves and tubers Note: A, B, C, D are diagrams of compounds found in tubers; while E, F, G, H, I are diagrams of compounds found in leaves

water with $0.1 \%$ formic acid (solvent A) and acetonitrile with $0.1 \%$ formic acid (solvent $\mathrm{B}$ ), and the flow rate was set at $0.3 \mathrm{~mL} / \mathrm{min}$. The gradient elution program for chromatographic separation was summarized in Table 1. In mass spectrometer, the extract was then ionized using electrospray

Table 2. Phytochemical composition of ethanol extracts of $A$. pusillus tubers

\begin{tabular}{lcclc}
\hline Compounds & RT & $\mathbf{~ m} / \mathbf{z}$ & \multicolumn{1}{c}{ Bioactivity } & Ref. \\
\hline Vitexin & 1.458 & 432 & $\begin{array}{l}\text { cardio-protective, anticancer, } \\
\text { anti-inflammation, antioxidant, } \\
\text { and anti-diabetic effects }\end{array}$ & (11) \\
\hline Orientin & 6.907 & 447 & $\begin{array}{l}\text { Anti-adipogenesis, } \\
\text { antibacterial, antiviral, } \\
\text { neuroprotective effects }\end{array}$ & (10) \\
\hline
\end{tabular}

Vitexin 2"-O- 10.994593

glucoside

Cyanidin 3-O- 3.628 $595 \quad$ Anti-leukemic activity

(15)

rutinoside

Table 3. Phytochemical composition of ethanol extracts of $A$. pusillus leaves

\begin{tabular}{lccc}
\hline \multicolumn{1}{c}{ Compounds } & RT & m/z Bioactivity & Ref. \\
$\begin{array}{l}\text { Pelargonidin 3-O- } \\
\text { glucoside }\end{array}$ & 3.867 & $\begin{array}{l}\text { 433 Anti-inflammatory } \\
\text { effect }\end{array}$ & (14) \\
\hline Schaftoside & 3.773 & $\begin{array}{l}565 \text { Antioxidant and } \\
\text { antinematodal drug }\end{array}$ & (23) \\
\hline $\begin{array}{l}\text { Vitexin 2"-O-glucoside } \\
\begin{array}{l}\text { Cyanidin 3-O- } \\
\text { rutinoside }\end{array}\end{array}$ & 11.005 & 593 \\
$\begin{array}{l}\text { Peonidin 3-O- } \\
\text { rutinoside }\end{array}$ & 9.657 & 595 Anti-leukemic activity (15) \\
\hline
\end{tabular}

ionization source (ESI) at positive mode and the mass spectra data were recorded on mode for a mass range $50-2000 \mathrm{~m} / \mathrm{z}$. Data Analysis software (Bruker, Germany) was used for data analysis.

\section{Antibacterial activities}

Evaluation of the antibacterial activity of ethanol extracts of $A$. pusillus leaves and tubers was carried out (8). The bacteria were inoculated into LB Broth for growing until the suspension reached the turbidity of 0.5 McFarland standards. $100 \mu \mathrm{l}$ of suspension were then spread on the surface of Mueller Hinton plate, and the sterilized $6 \mathrm{~mm}$ diameter discs were subsequently placed on. $20 \mu \mathrm{l}$ of ethanol extract were put onto the paper disc and the plates were maintained at $4^{\circ} \mathrm{C}$ for $2 \mathrm{hrs}$ for extract diffusion. The plates were incubated at $37^{\circ} \mathrm{C}$ for 24 hrs, and the diameter of the zone of inhibition of extracts against tested bacteria was measured. Sterilize distilled water and Gentamycin antibiotic discs (Nam Khoa BioTek, Vietnam) were used as negative and positive controls respectively.

The experiments of antibacterial activities were repeated in triplicate. The average and standard deviation were calculated as per Excel 2010. The data obtained from experiments were presented as mean \pm standard deviation (SD).

\section{Results and Discussion}

\section{Ethanol extract composition}

Based on comparison of mass of compounds $(\mathrm{m} / \mathrm{z})$ which were identified in $A$. pusillus with other compounds in Amorphophallus titanum, other 


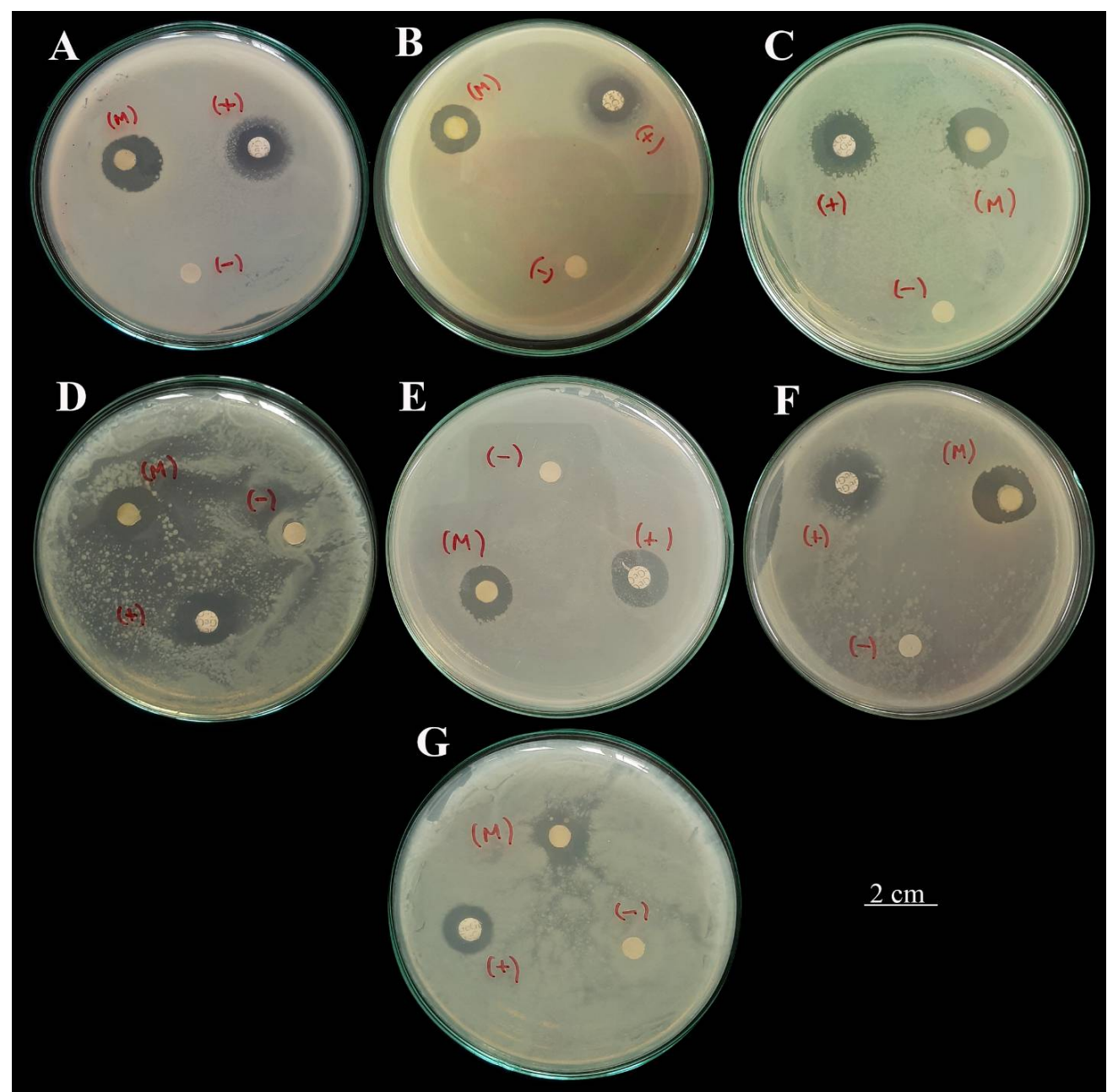

Fig. 3. Antibacterial activity of ethanol extracts from tubers and leaves of $A$. pusillus against test bacteria. A-F: leaves. A: B. cereus. B: E. coli. C: P. aeruginosa. D. S. typhimurium. E. S. enteritidis. F: S. aureus; G: S. typhimurium (tuber). (-) Negative control with sterilized distilled water, (+) Positive control with discs containing gentamycin, (M) sample of ethanol extract

member of Amorphophallus (9), we determined 7 compounds such as vitexin, orientin, vitexin $2 "-O$ glucoside, cyanidin 3-O-rutinoside, pelargonidin 3-Oglucoside, schaftoside and peonidin 3-O-rutinoside, which belong to flavonoid class in ethanol extracts of A. pusillus leaves and tubers. Among them, there were 3 anthocyanin compounds including pelargonidin 3-O-glucoside, cyanidin 3-O-rutinoside, peonidin 3-O-rutinoside, and 4 other flavonoids including vitexin, vitexin 2"-O-glucoside, orientin and schaftoside. Of note, vitexin 2"-O-glucoside and cyanidin 3-O-rutinoside existed in tubers and leaves of $A$. pusillus whereas vitexin and orientin were only found in tubers. On the other hand, pelargonidin 3-Oglucoside, peonidin 3-O-rutinoside and schaftoside were presented in leaves (Fig. 2 and Table 2, 3).

Flavonoid is a class of polyphenols with over 8000 compounds which characterizes by C6-C3-C6

Table 4. The inhibition zone of ethanol extract of A. pusillus leaves and tubers against five tested bacteria

\begin{tabular}{lcc}
\hline \multirow{2}{*}{ Tested bacteria } & \multicolumn{2}{c}{ Growth inhibition zone (mm) } \\
\cline { 2 - 3 } & Leaves & Tubers \\
\hline Bacillus cereus & $14.7 \pm 2.1$ & - \\
\hline Escherichia coli & $11.7 \pm 0.6$ & - \\
\hline Pseudomonas aeruginosa & $15.7 \pm 0.6$ & - \\
\hline Salmonella typhimurium & $16.2 \pm 0.8$ & $15.2 \pm 1.8$ \\
\hline Salmonella enteritidis & $12.3 \pm 1.5$ & - \\
\hline Staphylococcus aureus & $14.0 \pm 0.9$ & - \\
\hline
\end{tabular}

skeleton. Flavonoids are not only well-known antioxidants but also have bioactive compounds which exhibit several beneficial effects such as antiinflammation, anticancer and protection of cardiovascular illness (10). All of seven compounds which we identified in ethanol extracts of $A$. pusillus leaves and tubers are flavonoids. This finding suggests this species as a potential resource for extraction of bioactive compounds and further application in medicine. For example, vitexin, a constituent in $A$. pusillus tuber, is an apigenin flavone glycoside exhibiting several bioactivities such as cardio-protective, anticancer, anti-inflammation, antioxidant, anti-nociceptive, anticonvulsant, and anti-diabetic effects (11). It was also proved protective effect of vitexin in murine model of myocardial ischemia/reperfusion injury and suggested that the protective effect related to its potential for up-regulating Bcl-2 expression and down-regulating Bax and NF-kB p65 (12). Moreover, vitexin can diminish acute lung injury induced by lipopolysaccharide via enhancing the nuclear factor erythroid-2-related factor 2 (Nrf2) and activity of heme oxygenase (HO)-1 (13). Furthermore, orientin, another bioactive compound found in $A$. pusillus tuber, possesses a variety of beneficial effects such as anti-adipogenesis, anti-inflammation, antioxidant, anti-aging, antibacterial, antiviral, neuroprotective and antinociceptive (10). On the other hand, 
pelargonidin 3-O-glucoside, bioactive compound found in $A$. pusillus leaves has anti-inflammatory effect via increasing the interleukin 10 (IL-1), the predominant anti-inflammatory cytokine which is related to inhibition of pro-inflammatory cytokines, chemokines, macrophage activations, and may be supress atherosclerosis (14). Furthermore, cyanidin3-rutinoside, the anthocyanin found in both tubers and leaves of $A$. pusillus, selectively induces apoptosis in leukemic HL-60 cells via peroxides accumulation and altering the mitochondrial pathway (15). The presence of these bioactive compounds in A. pusillus has proposed a promising application of this species in medicine.

\section{Antibacterial activity}

Antibacterial activities of ethanol extracts of $A$. pusillus tubers and leaves were determined via diameter of the zone of inhibition against tested bacteria (Fig. 3 and Table 4). The results showed that ethanol extract of $A$. pusillus leaves could inhibit 6 tested bacterial strains, including $B$. cereus, $S$. aureus, $E$. coli, $P$. aeruginosa, $S$. enteritidis and $S$. typhimurium whereas that of $A$. pusillus tubers only hindered the growth of S. typhimurium. Among 6 bacterial strains, ethanol extract of $A$. pusillus leaves showed the strongest antibacterial activity against $S$. typhimurium $(16.2 \pm 0.8 \mathrm{~mm})$, followed by $P$. aeruginosa $(15.7 \pm 0.6 \mathrm{~mm}), B$. cereus $(14.7 \pm 2.1 \mathrm{~mm})$, $S$. aureus $(14.0 \pm 0.9 \mathrm{~mm}), S$. enteritidis $(12.3 \pm 1.5$ $\mathrm{mm})$, and $E$. coli with diameter of the zone of inhibition about $11.7 \pm 0.6 \mathrm{~mm}$. Otherwise, the ethanol extract of $A$. pusillus tubers exhibited a strong antibacterial activity against $S$. typhimurium with $15.2 \pm 1.8 \mathrm{~mm}$. In summary, the ethanol extract of $A$. pusillus tubers and leaves could inhibit all 6 tested bacteria.

These results are in line with previous studies which demonstrate the antibacterial activity of several species of Amorphophallus. For example, amblyone, a triterpenoid found in A. campanulatus, could hinder the growth of 10 bacterial strains including Streptococcus $\beta$-haemolyticus, Bacillus subtilis, Bacillus megaterium, $S$. aureus, Shigella dysenteriae, Shigella sonnei, Shigella flexneri, $P$. aeruginosa, Salmonella typhi and Escherichia coli (16). In previous study, various extracts of $A$. paeoniifolius exhibited antibacterial activity against $B$. subtilis, $S$. aureus, Klebsilla pneumonia, and $P$. aeruginosa (17). Furthermore, acetone and ethanol extracts of $A$. konkanensis also inhibited $B$. subtilis, M. aureus, $P$. aeruginosa, E. coli, S. typhi, and K. pneumoniae (18). Recently, it has been proved that ethanol extract of $A$. lanceolatus tuber could impede the growth of 6 bacteria, including $B$. cereus, S. aureus, E. coli, $P$. aeruginosa, $S$. enteritidis and $S$. typhimurium (6).

All of 7 compounds in this study belong to flavonoids, which exhibit a strong antibacterial effect against pathogenic microorganisms through the inhibition of nucleic acid synthesis, inhibition of cytoplasmic membrane function and energy metabolism altering the biofilm formation and membrane permeability (19). Therefore, the presence of these flavonoid compounds in A. pusillus tubers and leaves proposes an explanation for antibacterial activities of those resources. Furthermore, the difference of antibacterial activities between the tubers and leaves of $A$. pusillus may be owing to differences in chemical composition. Vitexin, the bioactive compound found only $A$. pusillus tubers, is suggested as an antibacterial agent against Enterobacter cloacae, Proteus mirabilis and E. coli (20). In the previous study, some bacteria such as $S$. aureus, Staphylococcus cohni, K. pneumonia were proved to be susceptible to orientin, other flavonoid in $A$. pusillus tubers (21). On the other hand, $A$. pusillus leaves contain 2 anthocyanin compounds, pelargonidin 3-O-glucoside and peonidin 3-Orutinoside, which are not found in tuber. Some anthocyanins may underlie the antimicrobial effect of several natural plants (22). These results suggests the potential application of ethanol extracts isolated from this species as natural antimicrobial compounds for the treatment of infection caused by bacteria, especially in dermatologic and enteric infections.

\section{Conclusion}

In this study, chemical compositions of $A$. pusillus leaves and tubers were elucidated with 7 flavonoid compounds, including vitexin, orientin, vitexin $2 "-O$ glucoside, cyanidin 3-O-rutinoside, pelargonidin 3-Oglucoside, schaftoside and peonidin 3-O-rutinoside in. Furthermore, ethanol extracts of $A$. pusillus leaves and tubers exhibited antibacterial effect against six tested bacteria such as $B$. cereus, $E$. coli, $P$. aeruginosa, $S$. enteritidis, $S$. typhimurium and $S$. aureus.

\section{Authors' contribution}

Hong Thien Van and Gia Buu Tran conceived and designed the study. Hong Thien Van, Hong Hai My Nguyen, Nguyen Tuong An Huynh, Van Son Le, Gia Buu Tran performed experiments and handled the research data. Hong Thien Van, Hong Hai My Nguyen, and Nguyen Tuong An Huynh conducted data analysis and interpreted the results. Hong Thien Van drafted the manuscript. Gia Buu Tran revised the manuscript. All authors read and approved the final manuscript.

\section{Acknowledgements}

The authors are grateful to Management, Board of Binh Chau-Phuoc Buu Nature Reserve, especially Mr. Le Van Khanh, Director of Binh Chau-Phuoc Buu Nature Reserve for their support during the field trip to collect the specimens.

\section{Completing interest}

The authors declare there is no conflict of interests.

\section{References}

1. Pham HH. Araceae. In: Pham HH, editor. An Illustrated Flora of Vietnam. Ho Chi Minh City: Youth Publishing House; 2000. p. 
$356-63$.

2. Boyce PC, Sookchaloem D, Hetterscheid WLA, Gusman G, Jacobsen N, Idei T, Nguyen VD. Araceae. The Flora of Thailand. 2002;11:130-86.

3. Nguyen VD. Flora of Vietnam-Araceae Juss. Vol. 16. Ha Noi (Vietnam): Publishing House for Sciense and Technology; 2017.

4. Tran VT, Ha VH, Nguyen MQ, Nguyen VD. Research component and distribution of species Amorphophallus spp. with tubers containing glucomannan in the Northern mountain provinces of Vietnam. Management of Forest Resources and Environment. 2017;5:118-25.

5. Singh A, Wadhwa NA. Review on multiple potential of Aroid: Amorphophallus paeoniifolius. International Journal of Pharmaceutical Sciences Review and Research. 2015;24:55-60.

6. Van HT, Tran NB, Trinh TT, Vo TNT, Le VS, Pham TV, et al. Phytochemical composition and antibacterial activity of ethanol extract of Amorphophallus lanceolatus tuber (Araceae). Banats Journal of Biotechnology [Internet]. 2019 [cited 2019 Dec 26];X(20):5-12. http://doi.org/10.7904/20684738-X(20)-5

7. Hetterscheid WLA, Claudel C. The end of Pseudodracontium N E. Br. Aroideana. 2012;35:40-46.

8. Bauer AW, Kirby WM, Sherris JC, Turck M. Antibiotic susceptibility testing by a standardized single disk method. American Journal of Clinical Pathology [Internet]. 1996 [cited 2019 Dec 26];45: 493-96. https://doi.org/10.1093/ajcp/45.4_ts.493

9. Iwashina T, Uehara A, Kitajima J, Yukawa T. Anthocyanins and other flavonoids from Amorphophallus titanum having largest inflorescence in plant kingdom, and other two species. Bull Natl Mus Nat Sci. Ser. 2015;41(1):33-44.

10. Lam KY, Ling APK, Koh RY, Wong YP, Say YH. A Review on Medicinal Properties of Orientin. Advances in Pharmacological Sciences [Internet]. 2016 [cited 2019 Dec 26]. https://doi.org/10.1155/2016/4104595

11. Aslam MS, Ahmad MS, Mamat AS. Pharmacological potential of vitexin. Indian Research Journal of Pharmacy and Science. 2015;2 (2):114-22.

12. Dong L, Fan Y, Shao X, Chen Z. Vitexin protects against myocardial ischemia/reperfusion injury in Langendorff perfused rat hearts by attenuating inflammatory response and apoptosis. Food Chem. Toxicol [Internet]. 2011 [cited 2019 Dec 26];49(12) 3211-16. https:// doi.org/10.1016/j.fct.2011.09.040

13. Lu Y, Yu T, Liu J, Gu L. Vitexin attenuates lipopolysaccharideinduced acute lung injury by controlling the Nrf2 pathway.
PLoS ONE [Internet]. 2018 [cited 2019 Dec 26];13(4): e0196405. https://doi.org/10.1371/journal.pone.0196405

14. Amini AM, Muzs K, Jeremy PE, Yaqoob P. Pelargonidin-3-O-glucoside and its metabolites have modest anti-inflammatory effects in human whole blood cultures. Nutrition Research [Internet]. 2017 [cited 2019 Dec 26];46: 88-95. https://doi.org/10.1016/j.nutres.2017.09.006.

15. Feng R, Ni HM, Wang SY, Tourkova IR, Shurin MR, Harada H, Yin XM. Cyanidin-3-rutinoside, a natural polyphenol antioxidant, selectively kills leukemic cells by induction of oxidative stress. Journal of Biological Chemistry. 2007;282(18):13468-76.

16. Khan A, Rahman M, Islam MS. Antibacterial, antifungal and cytotoxic activities of amblyone isolated from Amorphophallus campanulatus. Indian J Pharmacol [Internet]. 2008 [cited 2019 Dec 26];40(1):41-44. https://doi.org/10.4103/0253-7613.40489

17. Muthukumaran P, Saraswathy N, Yuvapriya S, Balan R, Venkatesh BG, Palanikumar I. In vitro phytochemical screening and antibacterial activity of Amorphophallus paeonlifolius (Dennst.) Nicolson against some human pathogens. Journal of Chemical and Pharmaceutical Research. 2016;8:388-92.

18. Chidanand CS, Suryakant W, Farida I, Nikhil G, Kumar P. Antibacterial activity of Amorphophallus konkanensis and Amorphophallus bulbifer tuber. Asian Journal of Pharmaceutical and Clinical Research. 2015;8:98-102.

19. Cushnie TPT, Lamb AJ. Review Antimicrobial activity of flavonoids. International Journal of Antimicrobial Agents. 2005;26:343-56.

20. Basile A, Giordano S, Antonio JLS, Cobianchi RC. Antibacterial activity of pure flavonoids isolated from mosses. Phytochemistry [Internet]. 1999 [cited 2019 Dec 26];52(8): 1479-82. https:// doi.org/10.1016/s0031-9422(99)00286-1

21. Ali H, Dixit S. In vitro antimicrobial activity of flavonoids of Ocimum sanctum with synergistic effect of their combined form. Asian Pacific Journal of Tropical Disease [Internet]. 2012 [cited 2019 Dec 26]; 2(1):396-98. https://doi.org/10.1016/S22221808(12)60189-3

22. Cisowska A, Wojnicz D, Hendrich AB. Anthocyanins as antimicrobial agents of natural plant origin. Nat Prod Commun. 2011;6(1):149-56.

23. PubChem Database. $\mathrm{CID}=442658$. [Internet]. Bethesda MD: National Center for Biotechnology Information; 2005 [updated 2020 Feb 15, cited 2020 Feb 26]. Available from: https://pubchem.ncbi.nlm.nih.gov/compound/Schaftoside 